\title{
Voltammetric and Quantum Investigation of Selected Succinimides
}

\author{
Bojan Božićl, Jelena Lović ${ }^{2}$, Nebojša Banjac ${ }^{3}, \check{Z ̌ e l j k o ~ V i t n i k}^{4}$, Vesna Vitnik ${ }^{4}$, Dušan Mijin ${ }^{5}$, \\ Gordana Uśćumlić, ${ }^{5}$ Milka Avramov Ivić, ,* $^{*}$ \\ ${ }^{1}$ Institute of Physiology and Biochemistry, Faculty of Biology, University of Belgrade, Belgrade, \\ Serbia \\ ${ }^{2}$ Institute of Electrochemistry, University of Belgrade, Belgrade, Serbia \\ ${ }^{3}$ Faculty of Agriculture, Food Technology and Biochemistry, University of Belgrade, Zemun, Serbia \\ ${ }^{4}$ Department of Chemistry, ICTM, University of Belgrade, Belgrade, Serbia \\ ${ }^{5}$ Department of Organic Chemistry, Faculty of Technology and Metallurgy, University of Belgrade, \\ Belgrade, Serbia \\ *E-mail: milka@tmf.bg.ac.rs
}

doi: $10.20964 / 2018.05 .54$

Received: 9 February 2018 / Accepted: 12 March 2018 / Published: 10 April 2018

\begin{abstract}
A series of succinimide derivatives were studied using the cyclic and square wave voltammetry. Density function theory was used in order to determinate which of the structural parameters influence the electrochemical activity. The quantum chemical calculations of the investigated succinimides were linked with the experimental electrochemical data and used to propose the oxidation mechanism. The most active among studied succinimides is 1,3-diphenylsuccinimide. The results obtained from the cyclic and square wave voltammetry and quantum chemical calculations indicate that the investigated compounds undergo oxidation by irreversible, diffusion controlled process including transfer of $1 \mathrm{e}^{-}$ and 1 proton. The voltammetric and DFT results signify that the mechanism of electrochemical oxidation of all compounds involve the conversion of carbonyl-methyne-phenyl segment or methylene group in free radical. This conversion proceeds by the loss of one proton one electron process.
\end{abstract}

Keywords: Diphenylsuccinimide, Threephenylsuccinimide, Voltammetry, Quantum chemical calculations, Reaction mechanisms

\section{$\underline{\text { FULL TEXT }}$}

(C) 2018 The Authors. Published by ESG (www.electrochemsci.org). This article is an open access article distributed under the terms and conditions of the Creative Commons Attribution license (http://creativecommons.org/licenses/by/4.0/). 